\title{
IDENTIFYING SOCIAL IMPACT FROM SUPPLEMENTAL EVENTS: A RESEARCH FRAMEWORK
}

\begin{abstract}
This paper develops a framework for identifying and fostering social impact for 'supplemental' (cultural, sporting and other) events which run in tandem with major sporting events. The framework links the aims of supplemental events with a classification of event activities in terms of achieved social impact and potential social benefits. Data supporting the study was collected from over 150 interviews conducted with tourists and local attendees at two supplemental events (Fan Zone and Trophy Tour) held in Australia as part of the 2015 International Cricket Council Cricket World Cup. Short-term social impacts emerging from the findings included a shared sense of community resulting from the atmosphere and ambience of the events. Potential longer-term social benefits, such as healthier lifestyles, were also identified by both tourists and locals. The framework enhances current understanding of strategies for fostering social impact and potential social benefits by providing an analytic tool to examine supplemental events and their effects on tourists and locals.
\end{abstract}

Keywords: Major sporting events; supplemental events; event leverage; social impact; social benefits; liminality strategies

\section{Introduction}

Major sporting events can provide short-term social benefits (impacts), which can then be leveraged into more durable social benefits that justify the large investments made in hosting them (Chalip 2004, 2006; O’Brien \& Chalip, 2007). While much of the literature on legacy focuses on economic benefits or infrastructural changes (Nitsch \& Wendland, 2016; Preuss, 2015), benefits can also include improving capacities at the individual and collective level, 
developing efficacy and social capital (Skinner, Zakus \& Cowell, 2008) and/or improving intergroup relations in divided societies through community based sport events (Kellett et al., 2008; Sugden, 2006). Major sporting events can be combined with regular sporting events and thus provide social opportunities, with disparate communities involved in the planning of related social and cultural activities (Schulenkorf \& Edwards, 2012), or 'supplemental' events. Preuss (2015, p. 643) advises caution, arguing 'it is not easy to identify sport event legacies in their entirety, because event-related changes may be confused with 'non' eventrelated development, and because a wide variety of areas and stakeholders are affected'. Smith (2014, p.15) noted that several studies investigating the social and economic impacts of major sporting events found that they 'are often disappointing'. Thus, the issue of legacy is complex, ranging from the potential for 'optimism bias' prior to the event, through to the difficulty of measurement after the event, differing stakeholder expectations and objectives, indirect external or environmental influences, and the intangibility and changing nature of community relationships (Kennelly, 2016; Minneart, 2012).

Chalip (2006) differentiated between early event studies that examined the economic and immediate social impact of events and later studies examining how event strategies were leveraged to create longer-term social benefits. Smith (2014) also differentiated between the shorter-term impacts of events and longer-term, pre-planned outcomes, but suggested that the boundaries between the two can be blurred. This paper focuses on shorter-term social impacts of events but also considers potential longer-term social benefits.

During events, the experience of liminality and communitas are often desired objectives for attendees and a means of leveraging potential social benefits (Chalip, 2006). Liminality involves a change in state amongst attendees: 
'...there is a sense that something more important - something that transcends the sport - is going on. It feels as if new energy has been injected into the communal atmosphere - an energy that can be shared by all. Social rules and social distinctions seem less important, and are sometimes suspended altogether. There is a heightened sense of community amongst those who are present' (Chalip 2006, p. 110).

Events have different effects on tourists and local resident attendees. For residents there is a clear potential for short-term social impact to be leveraged towards longer-term social benefits. Tourists often travel to escape their everyday lives and find themselves in situations that are suited to generating liminality (Jaimangal-Jones, Pritchard \& Morgan, 2010). However, the potential for longer-term social benefits may be limited as they return to their place of origin.

This article develops a framework that links the key stages of events as identified by Getz and Page (2020): planning and producing an event (the aims of supplemental events and planned activities), the event experience, and outcomes and impacts of the event. The framework is aimed predominantly at social impact, but also considers longer-term social benefits. The framework is illustrated by a case study of supplemental events hosted alongside the 2015 International Cricket Council (ICC) Cricket World Cup (CWC2015). Addressing calls for greater research on strategies and processes for successful event leveraging (Chalip, 2006; Ziakis, 2015), the framework extends Chalip's (2006) strategies for liminality creation at events. These are linked with Lauss and Szigetvari's (2010) classification of event activities and Smith's (2014) categorisation of social leverage objectives to identify social impact and potential social benefits for tourists and locals attending supplemental sporting events. Data collection involved over 150 semi-structured interviews at supplemental events associated with CWC2015, the Fan Zone and Trophy Tour. Fan Zones represent a phenomenon first 
noted at Euro 2004 but more widely formalised at the 2006 FIFA World Cup in Germany (Frew \& McGillivray, 2008; Klauser, 2011). Trophy Tours are usually associated with major sporting events or annual high-profile sporting competitions (Horne \& Whannel, 2010). The article first synthesises the relevant literature, then develops the proposed framework. The use of the case study methodology is outlined. The findings and their implications are considered. Finally, the contribution of the research to theory and practice is discussed.

\section{Literature Review}

In this section we discuss liminality and communitas at events and the role of supplemental events. A framework is introduced to examine strategies for creating social impact from supplemental events.

\section{Creating liminality and communitas at events}

Informed by Turner's (1969) early anthropological work, liminality is understood to have emerged from formal societal rituals, with ritual or sacred experiences generally labelled as being 'liminal', that is, a temporary state in between that from which one has come and that to which one is transitioning. More routine 'daily life' experiences, for instance, at festivals and carnivals, are generally described as 'liminoid' (a less precise, 'liminal like' term) (Getz \& Page, 2020; Turner, 1974; Van Gennep, 1960). The 'celebratory' nature of sporting events can create a limonoid space, allowing attendees to escape their everyday lives (Turner, 1984). Given this, 'liminoid' would be a more appropriate term to use in the context of major sporting events. However, Rowe (2008, p. 127) suggests this as 'unduly arbitrary', arguing that 'we see in the many forms of modern sports (as with modern forms of music, pictorial and performance art, literary forms and decorative arts) a common ritual legacy'. Fairley and O'Brien (2018) argued that the celebration of sport through events can have a wider societal 
significance and that the term 'liminality' is now commonly used in conjunction with sporting events.

The sense of celebration and camaraderie that can occur at such events are precursors to the creation of liminality and communitas (Chalip, 2006). Communitas refers to a shared sense of community among participants. Chalip (2006) suggested five strategies (described later) to foster social interaction and feelings of celebration to encourage liminality and communitas but argued that there was still much to be learned in respect of leveraging social benefits. Getz and Page (2020) discussed the different stages of events from an anthropological perspective, including planning and producing an event; the antecedents in place to influence attending an event; the event experience itself, and outcomes and impacts of the event. They discussed several factors related to the cultural importance of events. Planning and producing an event involve consideration of the organisers' aims as well as its stakeholders, who include local event organisers (such as local government and businesses), tourism promoters (Smith, 2010). This group would also include event sponsors. The media also play an important role. Major sporting events are a chance for sport governing bodies to promote themselves, as well as host cites (or countries) and sponsors. Sport governing bodies such as the ICC tend to keep tight control over media rights due to their revenue value and to protect the image that they promote (McGillivray, 2010).

Rites and rituals are patterned behaviours that can be used by event organisers to develop the event program. Getz and Page (2020) referred to Falassi's (1987) classification of rites and rituals, describing the entry to the event as a 'framing ritual' that indicates the space is special. The space is transformed with banners, branding and so forth to assist with this. Indeed, the spaces in which events are held are an important contributor to liminality and communitas. A space is delineated by its physical boundaries, but also how it is socially 
constructed (Jaimangal-Jones, 2010), for instance, how it encourages discourse between attendees during events. Shields (1990, p. 2) argued that 'space' underpins liminality as 'a socially defined zone appropriate for specific behaviours and patterns of interaction outside of the norms of everyday behaviour, dress and activity'. Crouch (2000) discussed the importance of space for individuals involved in leisure activities and tourism and described these spaces as 'sites of friendship and social engagement' that become meaningful through encounters with other people.

At events, such experiences are only available in-situ (Fairley \& O’Brien, 2018; Sterchele \& Saint-Blancat, 2015). King, Shipway, Lee and Brown (2018) suggested that tourists may be less bound by the 'mundane' than locals. Additionally, tourists' journey to the event can form part of their experience and increase the build-up and excitement associated with attending. In examining travel by dance enthusiasts to dance music events, Jaimangal-Jones et al. (2010) suggested that the temporary nature of such events potentially contributed to them being liminal spaces. These findings suggest that the experience of tourists attending supplemental events could differ from local attendees. For the tourist, liminality can involve a planned escape from a person's regular life to a different location. Experiences whilst away can lead to changed behaviours, reduced social barriers, shared experiences and a sense of belonging (Brooker \& Joppe, 2013).

Chalip (2006) discusses how liminality can be created by events, developing the preconditions for additional social leverage. He introduced five strategies for this purpose as detailed in Table 1. The table shows the two precursors for generating liminality followed by the strategies identified to achieve these.

[INSERT TABLE 1 HERE] 
Bingley et al. (2019) reviewed several studies that identified the creation of liminality and communitas at sporting events. Some of these examined supplemental events. For instance, Smith (2010) examined events surrounding Stage 1 of the 2010 Tour De France, held in South East England. Smith (2010) found that supplemental events can leverage benefits through association with the major event. Later, Smith (2014, p. 23) suggested that 'more research is needed to understand whether proximity to an events site is a critical success factor in event leverage'. More recently, a critical lens has been applied to the leveraging literature. Ziakis (2015) questioned the extent to which stakeholders and social groups benefit or are excluded from benefiting as a result of the leveraging process. Bell and Daniels (2015, p. 370) highlighted the positive, yet largely unproven, assumption that 'trickle-down' benefits flow from leveraging. Given this more critical turn and the research gaps noted thus far, it is timely to revisit Chalip's (2006) strategies as they relate to supplemental events to examine their potential for liminality creation and generation of short-term social impact and potential longer-term social benefits.

The literature on Fan Zones and Trophy Tours discussed below traverses several of Chalip's (2006) strategies for liminality creation. Chalip (2006) was moot as to whether his categorisations allow for such cross over. Regardless, the increasing use of these event engagement models has the potential to call into question the distinctiveness of Chalip's strategies and/or suggest some revision of or extension to them.

\section{Supplemental Events - Fan Zones and Trophy Tours}

Since the turn of the century 'Fan Parks, Fan Zones, Live Sites, Celebration Zones or public viewing areas' have operated as an extension of major sporting events (McGillivray \& Frew, 2015, p. 2650). Hereafter, the term 'Fan Zone' is used to describe these. Fan Zones are typically temporary areas set up in the host city, typically near event venues or in popular 
gathering spaces. Live matches are often broadcast on large screens in Fan Zones. These spaces provide scope to promote corporate sponsors (Klauser, 2011) and when designed as an enclosed area, can assist with managing the security of large crowds. Indeed, Fan Zones have been suggested as a positive, pre-emptive response to football hooliganism (Frew \& McGillivray, 2008; Lauss \& Szigetvari, 2010). Fan Zones use a 'fan centred approach' to create a positive 'atmosphere' (Grix, 2012) by offering a wide variety of activities to engage fans. Attendees, who often do not have tickets to the major sporting event, encounter security measures at entry to access the entertainment available in the Fan Zone. In their discussion of Fan Parks, McGillivray and Frew (2015, p. 2652) noted that 'the contrived spaces created at mega sports events have extended beyond mere ancillary events (Chalip, 2006) to become carefully planned, orchestrated and mediated events'. These sites offer opportunities for 'cocreated' experiences between event hosts, sponsors and participants. For instance, in the Olympics, sponsor branding often replaces other advertising during the event due to strict exclusivity clauses (McGillivray \& Frew, 2015).

Lauss and Szigetvari (2010)'s investigation of a Fan Zone associated with the 2008 European Football Championships held in Vienna classified the activities offered in the Fan Zone into different categories, namely:

- You are part of it all: where entry into an area allows the participant to feel part of the overall sporting event.

- Consume and design your own product: the authors provided an example of Adidas hosting an area where attendees could design and test their own athletic shoes.

- Be a (sport) star: opportunities for attendees to participate in sports related activities. 
- Be your own entertainer: the authors provided an example of portions of the Fan Zone crowd being broadcast onto a giant screen, often prompting those fans to behave in a manner that caused amusement for others.

- Let me entertain you: other forms of entertainment in the zones, such as concerts.

- Discover the beauty of (...): the event would be located near major landmarks and thus also be an advertisement for the area.

The discussion now turns to sporting Trophy Tours, which occur when the trophy being contested in an event is taken on 'tour' to different locations (before or after the event). For instance, the English Premier League's Chief Executive suggested that the league's global Trophy Tour showcased 'the league, its clubs and players, as it tours the globe...' (Bose, 2012, p. 14). In another example, Italian bank Unicredit sponsored a Trophy Tour for the UEFA Champions League (UCL) tournament that initially visited five of Unicredit's 'core' cities in $2009^{1}$. On the tour, the trophy travelled in a branded truck designed to attract attention - allowing people to experience the tour in areas that would not typically see the trophy. (Penna \& Guenzi, 2014). The chance to be close or to even touch the trophy provides a 'once in a lifetime' experience for fans. These examples suggest several aims associated with Trophy Tours: creating goodwill; attracting fans; promoting participation in the sport and acting as a vehicle for sponsors to showcase their brands. Recent (and current) Trophy Tours held at high profile major sporting events include the FIFA World Cup (2018), the Rugby Union World Cup (2019) and the AFC Asian Cup (2019). In Australia, the site of the

\footnotetext{
${ }^{1}$ The last UCL Trophy Tour sponsored by Unicredit was conducted in 2017 and included 16 Central and Eastern European countries where Unicredit had a presence. European and worldwide versions of the Tour have subsequently been sponsored by Nissan and Heineken.
} 
current study, Trophy Tours have been held annually for the Australian Open (Australia's tennis grand slam event) and the Melbourne Cup, Australia's premier horse racing event.

\section{A framework for linking event strategies to social impact and social benefits for supplemental events}

In this section, a framework is developed to link the aims of organisers and stakeholders to an event's social impact and potential short-term benefits. The framework initially considers the aims of event organisers and stakeholders. These are mapped to Lauss and Szigetvari's (2010) event activity categories. The framework also acknowledges the range of social impacts and potential social benefits that can occur through implementing Chalip's strategies with the former reflecting benefits to attendees occurring at the time of the event and the latter, the longer-term social benefits. To classify social benefits, we adopt Smith's (2014) categorisation of social leverage objectives. The framework template (illustrated in Table 2 below) is used to structure the current investigation and to discuss, in turn, each supplemental event examined. The framework provides greater clarity surrounding the activities that underpin Chalip's event liminality strategies (for supplemental events) and addresses his call for more research in the area (Chalip, 2006).

[INSERT TABLE 2 HERE]

\section{Methodology}

CWC2015 was held in venues across Australia and New Zealand. Cricket Victoria (CV), cricket's governing body in Victoria (a state of Australia), were the researchers' main liaison for CWC2015. Supplemental events examined were the Victorian sections of the CWC2015 Trophy Tour (held at multiple locations on different dates before the CWC2015 commenced) and the Melbourne Cricket Ground (MCG) Fan Zone. 
A case study research strategy was adopted with each supplemental event comprising a 'case'. Case studies can be used to understand complex social phenomena in a contemporary setting (Yin, 2018). Due to the inductive nature of the research and the need to investigate the responses of participants (Williamson \& Johanson, 2013), semi-structured interviews were the primary data collection method. Researcher observation (unstructured observation of the events) also formed an important part of the data collection. Interviews were conducted from late December 2014 until the end of CWC2015 on March 29, 2015. At least two interviewers collected data at each supplemental event and location. This was important as there were multiple entry and exit points to the events. The researchers estimated that a high proportion of people agreed to be interviewed (over 60\%).

The interview protocol, and most responses obtained, were brief. Interviews typically lasted five to ten minutes. Most of the questions were open-ended, providing a range of responses. Participants were asked demographic questions (age and gender) and then a series of questions related to their cricket background (if they or their children played cricket and, if so, at what level), motivations for attending the supplemental event (why they attended and how they heard about the event), what activities they had participated in and their evaluation of the event (the best aspects of the event and how it could be improved). They were also asked about their attitudes towards CWC2015.

Table 3 provides some respondent demographics. Overall, 152 interviews were conducted.

\section{[INSERT TABLE 3 HERE]}

Interviewees were classified as local residents, domestic tourists or international tourists. For Melbourne events, 'local' meant that interviewees lived in the CBD (Central Business District) or surrounding suburbs. Where the Trophy Tour was conducted in rural areas, 
'local' meant that participants lived in the local township. Participants who lived in Australia but not locally were classified as domestic tourists. All overseas visitors were classified as international tourists. Most Trophy Tour events were held in regional areas, so attendees were mostly locals or domestic tourists. A higher proportion of international tourists attended the MCG Fan Zone.

Interviews were not recorded as this would have provided an extra level of intrusion upon attendees in the outdoor event space and it was believed that they would therefore be less likely to agree to be interviewed. Interviews were written up by each interviewer at the end of each day. The analysis of the results was conducted by one of the authors using a combination of means. Baseline answers to questions were entered into a MS Excel spreadsheet, which allowed for simple demographic profiles to be determined. The bulk of the qualitative data was entered into the qualitative analysis software, NVivo. Themes emerging from the interviews were identified as subcategories for each event.

\section{Results and Discussion}

In this section, the results relating to the Trophy Tour and the MCG Fan Zone are discussed.

\section{ICC Cricket World Cup Trophy Tour}

In July 2014, the CWC2015 trophy began a tour of the participating nations, arriving in Australia and New Zealand in November 2014 and then visiting numerous places, including various locations in Victoria (five of which were selected for data collection). The activities offered at each site varied, typically including the chance to view and have a picture taken with the trophy, participate in cricket-based activities, watch international cricket on a giant screen (attached to a bus which accompanied the Trophy Tour) and participate in competitions. The locations are listed in Table 4.

[INSERT TABLE 4 HERE] 
Minneart (2012) and Kennelly (2016) discussed the importance of considering stakeholder aims at events. The main stakeholders for the Trophy Tour were the ICC (who provided guidelines for branding the event), CV (who organised tour events within Victoria, including arranging event staffing), local councils (who promoted local tour events on their websites and provided event spaces) and event sponsors.

For the events described in this paper, both the ICC and CV could be considered as coorganisers. They were interested in Chalip's (2006) enabling sociability and providing informal social opportunities by providing areas where people could gather and socialise during the Trophy Tour. Chalip's theme widely strategy was also adopted, with CWC2015 branding occurring through the presence of a large double decker bus and other highly recognisable signage. This supports the notion that more than one of Chalip's (2006) strategies can apply at the one event. Beyond their initial involvement, most local councils did not have a strong presence, beyond a few local council members visiting the events.

Several activities were present across the Trophy Tour. The opportunity to view live (preCWC2015) international cricket on a giant screen and the chance for attendees to have their picture taken with the trophy could be classified as you are part of it all as they helped people to feel included in the overall event. The cricket skills sessions could be classified as be $a$ sports star. Also, a competition to guess the number of cricket balls in the back of a sponsors' car could be classified as let me entertain you (Lauss \& Szigetvari, 2010). This was the only example of corporate sponsorship at the Trophy Tour events.

The space for the Trophy Tour was constructed differently in each location. The Geelong, Shepparton and Kinglake events were held in large park areas where all the activities could easily be viewed. The events at Wodonga and St Kilda were held in more urban settings, on 
smaller grassed areas with busy traffic and more passers-by. The tight space at Wodonga especially affected the experience of some attendees (as described later).

Getz and Page (2020) discussed how a space can be transformed with banners, branding and so forth. The ICC clearly took the opportunity to use the Trophy Tour events to promote themselves and participation in the game of cricket (a longer-term social benefit), rather than gaining additional revenue from corporate sponsorship. Whilst there were many examples of corporate sponsors' branding in and around the stadiums of CWC2015 matches, the status of the Trophy Tour as a supplemental event and its lesser exposure was likely the main reason for the lack of sponsors. However, CV indicated that the ICC controlled what could be displayed in the event spaces, which is in line with the notion that sport governing bodies like to control the narrative of such events (McGillivray, 2010).

The major mainstream (television and radio) advertising for CWC2015 typically did not promote supplementary events such as the Trophy Tour. The Trophy Tour was advertised on the ICC and CV's website, local council websites and social media pages, in local print and online media, and amongst cricket associations and clubs in the regions visited by the trophy. The promotional material typically mentioned the days that the trophy would be in certain locations and that there would be 'family friendly' activities. There was little evidence of McGillivray's (2010) suggestion of sport governing body influence over these materials, perhaps due to the Trophy Tour's status as a supplementary event.

Attendees were asked how they found out about the event. Whilst $42 \%$ indicated they were just 'passing by', $34 \%$ indicated they had seen some advertising about it and $20 \%$ found out from friends. 
Attendees were asked why they attended the event. Responses were taken from those who had planned to attend the event. The two major reasons mentioned were to view and photograph the trophy and for adults to keep their children occupied during school holidays. The best aspects of the event were the chance to view and/or be photographed with the trophy and the cricket-based activities. Viewing of the trophy was not as popular in Wodonga, probably because the trophy was positioned out of view (behind the tour bus) due to the tight space available. Attendees who were just passing by were not even initially aware that the trophy was there.

Nearly one third of attendees, mostly visitors who had planned to be at the event, commented that it was 'great' to see people having fun, being active or just playing games. Those who had planned their visit identified a broader range of 'best' aspects of the Trophy Tour than attendees who were just passing by, but otherwise there was little difference between the two groups. Local attendees noted people having fun and being active as the 'best' aspect. As would be expected, more locals noted the benefits of the event to the local community than tourists.

The Trophy Tour was conducted before CWC2015 commenced, so it was not a 'live' site. There was unrestricted entry to the Trophy Tour areas and minimal security in place. The organisational staff were involved in managing photographs with the trophy or organising cricket skills sessions. As described earlier, a liminal space may encourage participants to challenge the social boundaries of their everyday lives, with communitas resulting. When both ingredients are in place it may be possible to leverage the social benefits of sporting events (Chalip, 2006). For several reasons, the level of liminality generation at the Trophy Tour did not match the levels of a secured, live site where, say, a key match involving a home country was being broadcast. This was due to the nature of the space created and the fact that 
the Trophy Tour was conducted before CWC2015 commenced. However, it is possible to identify some themes emerging from the Trophy Tour interviews that could be described as short-term impacts and have the potential for longer-term social benefits. These were:

- Reverence to the trophy by attendees.

- Benefits for the local area where the trophy visited.

- People getting together and having fun - diversity and cultures mixing.

Reverence to the trophy [domestic tourists]. An interesting aspect of the Trophy Tour was the effort that tourists made to view the trophy. One Melbourne resident travelled by train to Geelong (a one-hour trip). He knew the trophy would visit Melbourne but thought that it would be too crowded. He donned a shirt from his country of origin (India) and had his picture taken with the trophy. Some interstate visitors flew in to see a cricket match (before the World Cup) and drove 90-minutes to Shepparton to see the trophy.

There was a feeling of reverence towards the trophy. Some typical comments were: 'It's not every day you get to see the trophy' [Local].

'We actually got to touch the trophy' [Domestic tourist].

The fact that people were prepared to travel to see the trophy suggests that it held some meaning to them, consistent with it being a once-in-a-lifetime experience (Penna \& Guenzi, 2014). This can be viewed as a social impact as participants took pleasure in attending and seeing the trophy.

Benefits for local area [Locals]. The Trophy Tour visited many areas where major events are not typically held. Local attendees suggested that the visit of the trophy was good for their area:

'It's really good that they brought it to Geelong' [Local]

'These things don't come to Shepp (Shepparton) often' [Local]. 
'We are lucky and fortunate to have it here' [Local].

'It's not something that happens very often in the area let alone the country' [Local].

Attendees expressed appreciation that organisers brought the trophy to their area. There was a 'feel good' factor about this (an immediate social impact). Some attendees suggested that the trophy visit provided a boost to cricket (and sport in general) in the area, which implied potential longer-term social benefits.

However, in Kinglake, the tour had a different meaning. The township and surrounding areas were ravaged by bushfires in 2009, which lead to severe loss of life and property. CV brought the trophy to Kinglake to specifically provide a boost to the area. One attendee said that after the bushfires, many players did not see cricket as a high priority and were lost to local clubs, with some members suffering from isolation. Thus, the trophy visit was viewed as an opportunity to bring the community together. Many attendees talked about how good it was to see local people there and suggested that it would be good to hold similar events. Some discussed feelings of isolation and depression since the bushfires and mentioned how such events provided friends with opportunities to socialise. This was a very localised finding and was unlikely to be experienced as strongly by domestic or international tourists. Thus, the event in this location provided social impacts and potential social benefits in a different manner to the other areas.

People getting together and having fun - diversity and cultures mixing. Another benefit of Trophy Tours identified in the literature was their potential to generate goodwill. This was a strong theme in the data. Attendees commented that it was good to see communities, friends and families gathering together. In addition, there were many comments about the diversity of attendees and mixing cultures. In Shepparton, nearly one in five interviewees mentioned the mixing of different cultures in the skills sessions as one of the best aspects of the event: 
'...just have to look around and see the diversity and different cultures at the event which is really good to see. The event brings people in the community together' [Local].

'A good community event and nice to see the public engaging with it and kids playing cricket' [Local].

'It is great seeing people from every culture together' [Domestic tourist].

These comments referred to the social impact of the tour rather than any longer-term social benefits.

As mentioned earlier, tourism and leisure spaces can be meaningful through encounters between people through friendship and social engagement. As most of the tour events were conducted in regional areas, many of the local attendees knew each other and congregated in small groups, often as their children participated in the activities. As such, whilst the space provided opportunities for children (and some adults) to participate in physical activity, the residue of attendees typically stood or sat in small groups. As referred to in the interviewee comments, this was a strength of the tour events. Thus, the spaces certainly encouraged discourse between attendees.

There were examples of both social impact and potential social benefits at the Trophy Tour events (Chalip, 2006; Smith 2014). Some social impacts were related to specific activities (viewing the World Cup trophy and skills sessions), whereas others (the tour being good for the local area and encouraging community gathering) referred to the overall event. Local attendees were more likely to recognise the benefits of the tour for the local area, whilst some domestic tourists went out of their way to travel great distances to see the trophy. Several potential social benefits to be realised over time were also identified by interviewees. 
Mapping to the research framework

Table 5 maps the Trophy Tour strategies, activities and outcomes to the research framework template.

[INSERT TABLE 5 HERE]

The discussion now moves onto the MCG Fan Zone.

\section{Melbourne (MCG) Fan Zone}

CWC2015 Fan Zones were held at many World Cup venues. In Melbourne, the Fan Zone was located at Birrarung Marr, parkland between the city centre and the MCG. Data was collected from the Fan Zone during four of the five Melbourne matches, including a quarterfinal match and the final. Differing from Fan Zones in the literature, the MCG Fan Zone was not fenced in and did not have a high level of security. Additionally, tickets were readily available for most of the live matches (except the final) and matches were also broadcast live on free-to-air television. As such, the Fan Zone was mostly supplemental to, and not a substitute for, spectators experiencing the live event.

With regards to important stakeholders at the events (Minneart, 2012; Kennelly, 2016), those involved in the Fan Zone organisation were the ICC, CV (who again arranged staff at the events) and the local council (the City of Melbourne, who provided the event spaces). This involvement was similar to the Trophy Tour events. There was no corporate sponsors associated with the Fan Zone events, which was perhaps a missed branding and revenue opportunity for CWC2015.

In terms of Chalip's (2006) strategies for encouraging liminality, the Fan Zone allowed for enabling sociability, providing areas where people could gather and socialise. Similarly, the theme widely strategy was adopted, with CWC2015 and ICC branding occurring through 
recognisable signage. The branding (signage) was controlled by the ICC and promoted the ICC, the World Cup and participation in cricket (as a longer-term social benefit). The Fan Zone also provided informal social opportunities, a space away from the main venue where people could gather to watch the matches. The opportunity to view cricket on a giant screen and attendees having their faces or nails painted in their countries' colours are classified as 'you are part of it all'. Cricket skills clinics are classified into the 'be a sports star' category (Lauss \& Szigetvari, 2010). The Fan Zone was an experience for attendees who were on their way to World Cup matches (before the match) or for visitors to the area during the match to watch it live. Most visitors were on their way to the match; hence the space was sparsely populated once matches commenced.

The Fan Zone was held at two different locations during the World Cup. In the first match it was held in a large, waterlogged (from rain the previous day) grassed area. Whilst there was plenty of space to set up the activities, potential attendees were therefore limited to match attendees as there were few other passers-by. Even match attendees had to be part way over a pedestrian bridge before they spotted the zone. That meant that there was only a small number of attendees and most of those had planned to attend the event. For the remaining match days, the zone was moved to a more central area, directly on the path for spectators walking from the CBD to the match. It was still a large space that allowed attendees to easily view the activities on offer. On these days attendance at the Fan Zone increased and was dominated by passers-by. This is an example of how important the location of an event space can be.

As with the Trophy Tour, mainstream advertising for CWC2015 did not promote the Fan Zone. Generally, there was less media promoting the MCG Fan Zone than the Trophy Tour events. It was promoted on the ICC website as well as on CV's social media and the local 
council (Melbourne) website. The promotional material mentioned the dates that the Fan Zone would be operational and that it would be accompanied by 'cricket related' activities. The status of the Fan Zone as a supplementary event may have contributed to the ICC not influencing the content of these promotions, as might otherwise be expected from a sport governing body (as per McGillivray, 2010).

Most attendees, (62\%) were just 'passing by'. Only 17\% indicated that they had seen advertising about the event and $21 \%$ had either been to another Fan Zone or heard about it by word of mouth.

The small proportion of participants who planned to attend were asked why they attended. Three-quarters had no specific activity in mind but knew there would be activities there. A small proportion (15\%) indicated they attended for the skills sessions.

As with the Trophy Tour, the best appreciated aspects of the Fan Zone were seeing people having fun, being active and the positive atmosphere generated by the event. There was little difference in the responses of people who had planned to attend the event and passers-by. Additionally, the level of liminality generation in the Fan Zone did not match the levels that could be achieved in a secured, live site. This was likely due to the open spaces created and that most attendees were going to the match - thus the site was not actually a 'live' experience. However, it was interesting that $40 \%$ of international tourists identified the Fan Zone ambience and/or atmosphere generated as its best aspect, so this suggests a distinct, experience for those attendees. Being away from home, this group could potentially have experienced reduced social barriers and shared experiences (Brooker \& Joppe, 2013). There were two major themes emerging from the Fan Zone interviews:

- People getting together and having fun.

- The atmosphere and ambience of the event. 
People getting together and having fun. This was a strong theme that emerged. Typical comments were:

'Excellent, good to have, nice to see families and people getting involved and being part of the match day experience and atmosphere' [Domestic tourist].

'It's good to see the community get involved in these events' [Local].

'I enjoyed having fun and playing cricket in the nets with my son' [International tourist]. These comments related to shorter-term social impacts rather than potential longer-term social benefits.

Atmosphere and Ambience. Even though conditions did not encourage liminality as may have occurred in a closed 'live site', several attendee comments mentioned the atmosphere generated:

'It is a great atmosphere, excitement from everyone around' [International tourist]. 'The whole event really adds to the buzz so gets everyone pumped up. There is a buzz in the area. You feel part of the game and the whole match day experience. By playing in the nets you really get to feel part of the sport and included in it'. [International tourist].

'Excellent, good to have, nice to see families and people getting involved and being part of the match day experience and atmosphere' [Domestic tourist].

Again, these comments were more related to shorter-term social impacts.

Both major themes that emerged reflected outcomes consistent with the Fan Zone literature, particularly feeling part of the overall major event and the atmosphere generated.

Most of the attendees at the Fan Zone turned up in small groups (usually heading to the day's match). One of the major differences between the Fan Zone and Trophy Tours events was that the different groups that attended typically did not know each other (as they came from different regions and countries). Despite this, these groups (typically parents or guardians or 
groups of friends) formed small discussion groups as their children or friends participated in the physical activities. Thus, the setup of the Fan Zone spaces encouraged discourse between attendees.

As with the Trophy Tour, there were instances of both social impact and potential social benefits at the Fan Zone events (Chalip, 2006; Smith 2014). The sporting activities were popular with attendees, with the potential identified for further involvement in sport over the longer-term, with associated health benefits. Once again, the impact of the community gathering together was highlighted, particularly the positive atmosphere and ambience of the event. This was mostly (but not exclusively) highlighted by international tourists.

\section{Mapping to the research framework}

Table 6 maps the MCG Fan Zone relative to the research framework template.

\section{[INSERT TABLE 6 HERE]}

\section{Contributions and Implications}

The current study uses two supplemental events associated with CWC2015 to illustrate the suggested research framework. The study extends Chalip's (2006) strategies by integrating them with Lauss and Szigetvari's (2010) classification of event activities and Smith's (2014) categorisation of social leverage objectives to propose a framework template that may be put to useful effect in planning for social impact and social benefits.

As can be seen in Table 5 and Table 6, it is possible to map the findings from both supplemental events to see the progression from event aims to event outcomes. There would be value in exploring the merit of the proposed framework for identifying and fostering liminality and the generation of social impacts and social benefits in respect of other major events. Additionally, there is also scope to study how elements of event design and space contribute to these given the findings suggested that the open space of the supplemental 
events, the many entry points and the lack of 'live' broadcasts meant that the levels of liminality suggested in the literature were not achieved. Based on the Trophy Tour findings, there was also support for Smith's (2010) notion that benefits can be leveraged from minor events (held at a distance) affiliated with major events. With regards to the aims of event stakeholders, whilst ICC branding and corporate sponsorship were visible at the supplemental events, there was little mention of the ICC by interviewees and virtually no mention of the corporate sponsor at the Trophy Tour. Local councils where the Trophy Tour visited would likely have been pleased at the turnout to the events.

There were also important findings with regards to the experience of locals versus domestic and international tourists. Some social impacts and potential social benefits were mentioned only by locals. For instance, mostly domestic tourists mentioned that the feeling of viewing the World Cup trophy was special and appeared to hold it in some reverence. Liminality (of a limited level) was mostly generated amongst tourists. International tourists at the Fan Zone mentioned the atmosphere and the ambience of that event, these hinting at the type of feelings described as the generation of liminality.

In future research, the framework could be used by researchers to provide a lens by which they are able to link the earlier, anthropological notions of liminality (or liminoid spaces) (Turner, 1969), rites and rituals and the importance of space associated with the planning of events. This would support calls in the events literature (Baum, Lockstone-Binney \& Robertson, 2013; Getz, 2012) for more classical discipline-based studies that draw upon established social science disciplines to explain event experiences. Additionally, planners and organisers of sporting events could use the framework to consider the aims of their events and the types of supplementary events that they run to maximise ensuing social impact and 
benefits. Subsequently, the framework might serve as an evaluation tool to assess the expected versus actual social impact and benefits achieved.

\section{Conclusion}

Chalip's liminality strategies were found to be important to the supplemental events associated with the CWC2015. These strategies were similar for both the Fanzone and Trophy Tour, despite differences in the focus, timing and location of these events. Indeed, except for access to the trophy, most activities were present in both events.

Providing greater descriptive depth to Chalip's (2006) strategies, the Fan Zone activity classification of Lauss and Szigetvari (2010) was useful for describing the scope of activities utilised. Of those, you are a part of it all and be a sports star were the activities common to both supplemental events, allowing attendees to participate in sporting activities and/or gain a sense of being part of CWC2015.

Some social impacts and potential benefits were identified but these generally did not result from liminality generation (for example, feeling of reverence in relation to the Trophy Tour). This suggests that the organisers did not capitalise on the full range of liminality strategies and activations outlined in the framework, in addition to failing to match the sponsorship leveraging opportunities and the atmospheric benefits of branded, securitised and wholly live sites.

The study adds to the event liminality and leveraging for social impact and social benefits literature by extending understanding of Chalip's (2006) strategies using two supplemental events of the CWC2015. It also adds to practice by developing a framework that can aid in planning for liminality generation and leverage of social benefits at supplemental events. The limitations of the study should be noted. The framework developed was applied only to CWC2015 supplemental events in a single region (Victoria), when the event was held across 
Australia and New Zealand. Additionally, the framework was not used in planning for the event, so its operation as a planning tool would need to be tested. Furthermore, the framework was applied in respect of the supplemental events of a one-sport event, as opposed to multi-sport events such as the Olympic Games.

\section{References}

Bell, B., \& Daniels, J. (2018). Sport development in challenging times: Leverage of sport events for legacy in disadvantaged communities. Managing Sport and Leisure, 23(4-6), 369-390.

Baum, T., Lockstone-Binney, L., \& Robertson, M. (2013). Event studies: Finding fool's gold at the rainbow's end? International Journal of Event and Festival Management, 4(3), 179-185.

Bingley, S., Burgess, S., Lockstone-Binney, L., \& Urwin, G. (2019). Liminality Creation Strategies at Supplemental Events. Event Management, 23(6), 939-943.

Bob, U., \& Swart, K. (2010). The 2010 FIFA World Cup and women's experiences in fan parks. Agenda, 24(85), 85-96.

Bose, M. (2012). Game Changer: How the English Premier League came to dominate the world. Marshall Cavendish.

Brooker, E., \& Joppe, M. (2013). Developing a tourism innovation typology: Leveraging liminal insights. Journal of Travel Research, 53(4), 500-508.

Chalip, L. (2004). Beyond impact: A general model for sport event leverage. In B. W. Ritchie \& D. Adair (Eds.), Sport tourism: Interrelationships, impacts and issues (pp. 226252). Channel View Publications.

Chalip, L. (2006). Towards social leverage of sport events. Journal of Sport \& Tourism, 11(2), 109-127.

Crouch, D. (2000). Places around us: embodied lay geographies in leisure and tourism. Leisure Studies, 19(2), 63-76. 
Derom, D., \& VanWynsberghe, R. (2015). Extending the benefits of leveraging cycling events: Evidence from the tour of Flanders. European Sport Management Quarterly, 15(1), 111-131.

Fairley, S. \& O’Brien, D. (2018). Accumulating subcultural capital through sport event participation: The AFL International Cup. Sport Management Review, 21(3), 321-332.

Falassi, A. (1987). Festival: Definition and morphology. In. A. Falassi. (Ed), Time out of Time: Essays on the Festival (pp. 1-10). University of New Mexico Press.

Frew, M., \& McGillivray, D. (2008). Exploring hyper-experiences: Performing the fan at Germany 2007. Journal of Sport \& Tourism, 13(3), 181-198.

Getz, D. (2012). Event studies: Discourses and future directions. Event Management, 16(2), 171-187.

Getz, D., \& Page, S. (2020). Event Studies: Theory, Research and Policy for Planned Events, 4th Ed, Routledge.

Grix, J. (2012). "Image" leveraging and sports mega-events: Germany and the 2006 FIFA World Cup. Journal of Sport \& Tourism, 17(4), 289-312.

Horne, J., \& Whannel, G. (2010). The 'caged torch procession': Celebrities, protesters and the 2008 Olympic torch relay in London, Paris and San Francisco. Sport in Society, 13(5), 760-770.

International Olympic Committee. (2016). Factsheet: The Olympic Torch Relay. International Olympic Committee.

Jaimangal-Jones, D. (2010). Exploring the construction and consumption of dance music spaces through the liminal lens. In J. Lovell, \& M. Stuart-Hoyle (Eds.). Leisure Experiences: Space, Place and Performance (pp. 143-164). Leisure Studies Association.

Jaimangal-Jones, D., Pritchard, A., \& Morgan, N. (2010). Going the distance: locating journey, liminality and rites of passage in dance music experiences. Leisure Studies, 29(3), 253-268.

Kellett, P., Hede, A., \& Chalip, L. (2008). Social policy for sport events: leveraging (relationships with) teams from other nations for community benefit. European Sport Management Quarterly, 8(2), 101-122. 
Kennelly, J. (2016). Olympic exclusions: Youth, poverty and social legacies. Routledge.

King, K., Shipway, R., Lee, I., \& Brown, G. (2018). Proximate tourists and major sport events in everyday leisure spaces. Tourism Geographies, 20(5), 880-898.

Klauser, F. (2011). The exemplification of 'Fan zones' mediating mechanisms in the reproduction of best practices for security and branding at EURO 2008. Urban Studies, 48(15), 3203-3219.

Lauss, G., \& Szigetvari, A. (2010). Governing by fun: EURO 2008 and the appealing power of fan zones. Soccer \& Society, 11(6), 737-747.

Linsi, U. (2007). Money and sport: How they are compatible. Finance \& Bien Commun, 26(1), 36-39.

McGillivray, D. (2014). Digital cultures, acceleration and mega sporting event narratives. Leisure Studies. 33(1), 96-109.

McGillivray, D., \& Frew, M. (2015). From fan parks to live sites: Mega events and the territorialisation of urban space. Urban Studies, 52(14), 2649-2663.

Minnaert, L. (2012). An Olympic legacy for all? The non-infrastructural outcomes of the Olympic Games for socially excluded groups (Atlanta 1996-Beijing 2008). Tourism Management, 33(2), 361-370.

Nitsch, V., \& Wendland, N. (2016). The IOC's midas touch: Summer Olympics and city growth. Urban Studies, 54(4), 971-983.

O’Brien, D., \& Chalip, L. (2007). Sport event and strategic leveraging: Pushing towards the triple bottom line. In A. Woodside \& D. Martin (Eds.). Tourism management: Analysis, behaviour and strategy (pp.318-338). CABI.

Penna, D., \& Guenzi, P. (2014). How to use a sponsorship platform to support an international master brand strategy: The UniCredit UEFA champions league sponsorship. Journal of Brand Management, 21(2), 133-149.

Preuss, H. (2015). A framework for identifying the legacies of a mega sport event, Leisure Studies, 34(6), 643-664.

Rowe, S. (2008). Modern sports: liminal ritual or liminoid leisure. In: G. St. John. (Ed.) Victor Turner and Contemporary Cultural Performance. (pp. 127-148). Berghan Books. 
Schnitzer, M., \& Stickdorn, M. (2012). Key success factors for fan zones (public viewings) covering mega sport events - the case of UEFA EURO 2008 (TM) in Austria. European Journal of Tourism Research, 5(1), 19-37.

Schulenkorf, N. \& Edwards, D. (2012). Maximizing positive social impacts: strategies for sustaining and leveraging the benefits of intercommunity sport events in divided societies. Journal of Sport Management, 26(5), 379-390.

Shields, R. (1990). The 'System of Pleasure': Liminality and the Carnivalesque at Brighton, Theory, Culture \& Society, 7(1), 39-72.

Skinner, J., Zakus, D., \& Cowell, J. (2008). Development through sport: building social capital in disadvantaged communities. Sport Management Review, 11(3), 253-275.

Smith, A. (2010). Leveraging benefits from major events: Maximising opportunities for peripheral urban areas. Managing Leisure, 15(3), 161-180.

Smith, A. (2014). Leveraging sport mega-events: New model or convenient justification? Journal of Policy Research in Tourism, Leisure and Events, 6(1), 15-30.

Sterchele, D., \& Saint-Blancat, C. (2015). Keeping it liminal. The Mondiali Antirazzati (Anti-racist World Cup) as a multifocal interaction ritual. Leisure Studies, 34(2), 182196.

Sugden, J. (2006). Teaching and playing sport for conflict resolution and co-existence in Israel. International Review for the Sociology of Sport, 41(2), 221-240.

Turner, V. (1969). The ritual process: Structure and anti-structure. Aldine Publishing.

Turner, V. (1974). Liminal to liminoid, in play, flow, and ritual: an essay in comparative symbology. Rice Institute Pamphlet-Rice University Studies, 60(3), 53-92.

Van Gennep, A. (1960). The rites of passage. Routledge.

Williamson, K., \& Johanson, G. (Eds.). (2013). Research methods: Information, systems and contexts. Tilde University Press.

Yin, R.K. (2018). Case study research and applications : design and methods. $6^{\text {th }}$ ed. Sage.

Ziakis, V. (2015). For the benefit of all? Developing a critical perspective in mega-event leverage. Leisure Studies, 34(6), 689-702. 